\title{
In Situ TEM Study of Chemical and Structural Transformation of Carbon Coated Titania Nanoparticles
}

\author{
M. Pozuelo ${ }^{1}$, S.V. Prikhodko ${ }^{1}$, X. Zhang ${ }^{2}$, J.H. Park ${ }^{1}$, R. Koc ${ }^{3}$, S. Kodambaka ${ }^{1}$ \\ ${ }^{1}$ Dept. Materials Science and Engineering, UCLA, Los Angeles, CA 90095 \\ ${ }^{2}$ Hitachi High Technologies America, Inc., Pleasanton, CA 94588 \\ ${ }^{3}$ Dept. Mechanical Engineering, Southern Illinois University at Carbondale, IL 62901
}

Metal carbides such as titanium carbide (TiC) form a technologically-important class of materials with applications in catalysis, energy storage, high-temperature corrosion- and oxidation-resistant coatings, and structural composites [1-4]. For all these applications, high surface area, small size, and control over the phase purity are desirable. One of the most common methods for TiC synthesis is carbothermal reduction of $\mathrm{TiO}_{2}$ at elevated temperatures. It occurs via successive formation of lower oxides of titanium along with the emission of $\mathrm{CO}$ and $\mathrm{CO}_{2}$. However, atomic-scale insights into the mass transport mechanisms, chemical reaction pathways, and the material thermodynamics underlying the carbothermal reduction synthesis, which control the final particle size, shape, and crystal structure, are largely unknown.

Our experiment was carried out on carbon-coated titania powders. Particles with average size $\sim 20$ $\mathrm{nm}$ were loaded into an oxygen-free tube furnace and heated at $\sim 600{ }^{\circ} \mathrm{C}$ in a propylene $\left(\mathrm{C}_{3} \mathrm{H}_{6}\right)$ at ambient pressure. It resulted in a uniform coating of titania with $\sim 2-5 \mathrm{~nm}$ pyrolytic carbon shells. In situ heating experiments were carried out on H-9500 (Hitachi) and Titan (FEI) TEMs both operating at $300 \mathrm{kV}$. The oxide-core/C-shell nanoparticles were deposited directly onto a heating filament of the gas injection-heating TEM sample holder of Hitachi system and on TEM grids using Hummingbird heating stage on Titan. Images were acquired at video rate while heating the particles in TEM column up to $900{ }^{\circ} \mathrm{C}$ and for up to $5 \mathrm{~h}$. Carrying out such experiments in situ in the TEM allows us to monitor all transformations in real time.

We found that both titania core nanoparticles as well as the carbon shell undergo significant changes during temperature-controlled annealing. Titania core nanoparticles demonstrate tendency in reduction of the oxidation state to lower oxides. Carbon shells, mostly amorphous at room temperature undergo early stages of graphitization at temperatures above $600{ }^{\circ} \mathrm{C}$. Our observation suggests that graphitization is promoted by specific orientation of certain facets of titania core. It is well known that the graphitization in bulk requires much higher temperatures [6]. Finally we directly observed formation of hollow-core graphitic shells.

\section{References}

[1] S.T. Oyama, Catal. Today 15, 179 (1992).

[2] P. Patel, I.S. Kim, P.N. Kumta, Mater. Sci. Eng. B 116, 347 (2005).

[3] M.M. Opeka, I.G. Talmy, J.A. Zaykoski, J. Mater. Sci. 395887 - 5904 (2004).

[4] I.A. Ibrahim, F.A. Mohamed, E.J. Lavernia, J. Mater. Sci. 26, 1137 (1991).

[5] R. Koc, J. Mater. Sci. 331049 - 1055 (1998).

[6] B.T. Kelly, Physics of Graphite. Applied Science Publishers, London, 1981 

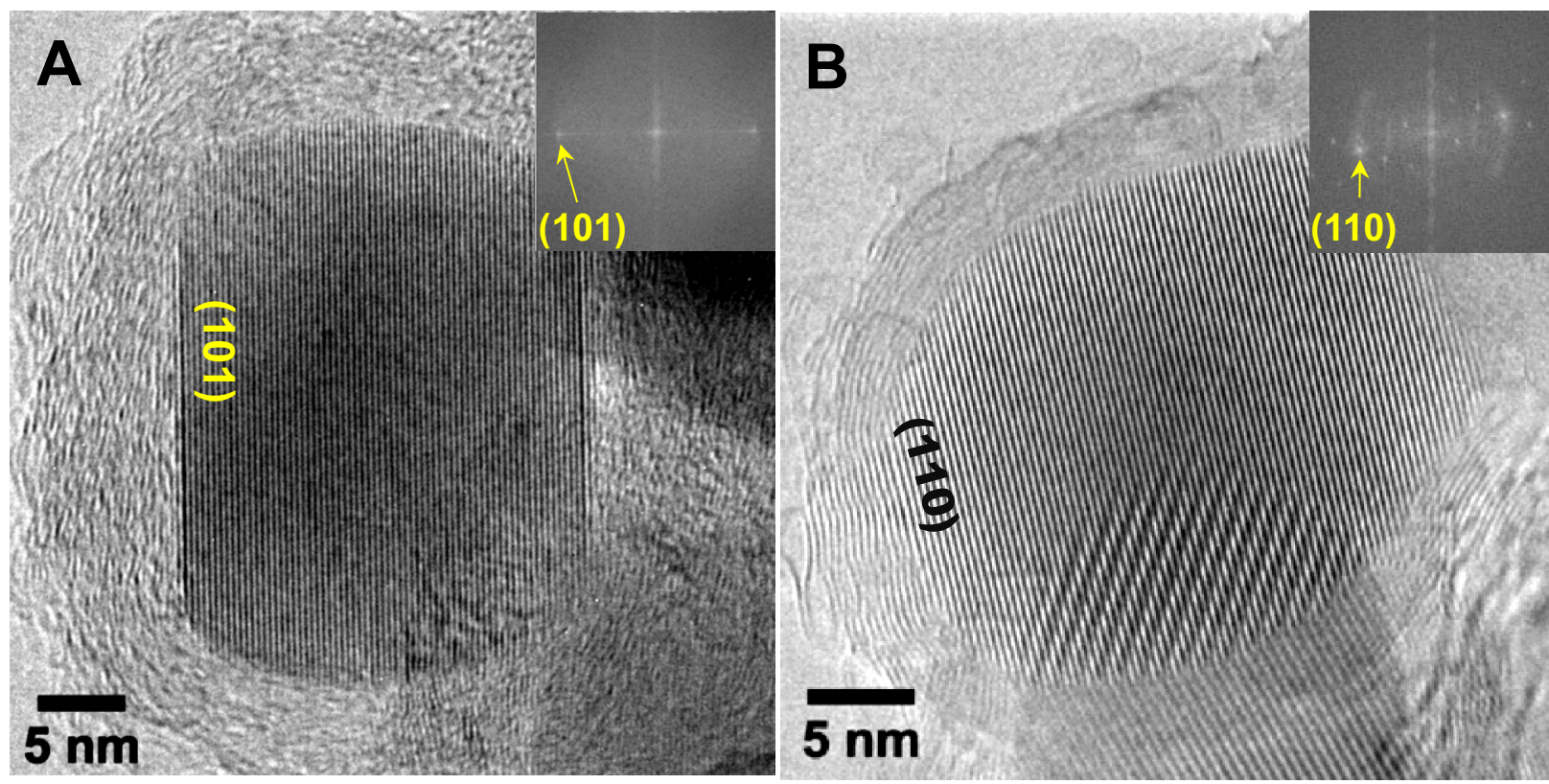

Figure 1. Images of titania-carbon core-shell particles demonstrate early stages of graphitization of carbon shells on particular facets (highlighted) of anatase (A) and rutile (B) taken at 600 and $700{ }^{\circ} \mathrm{C}$ respectively.
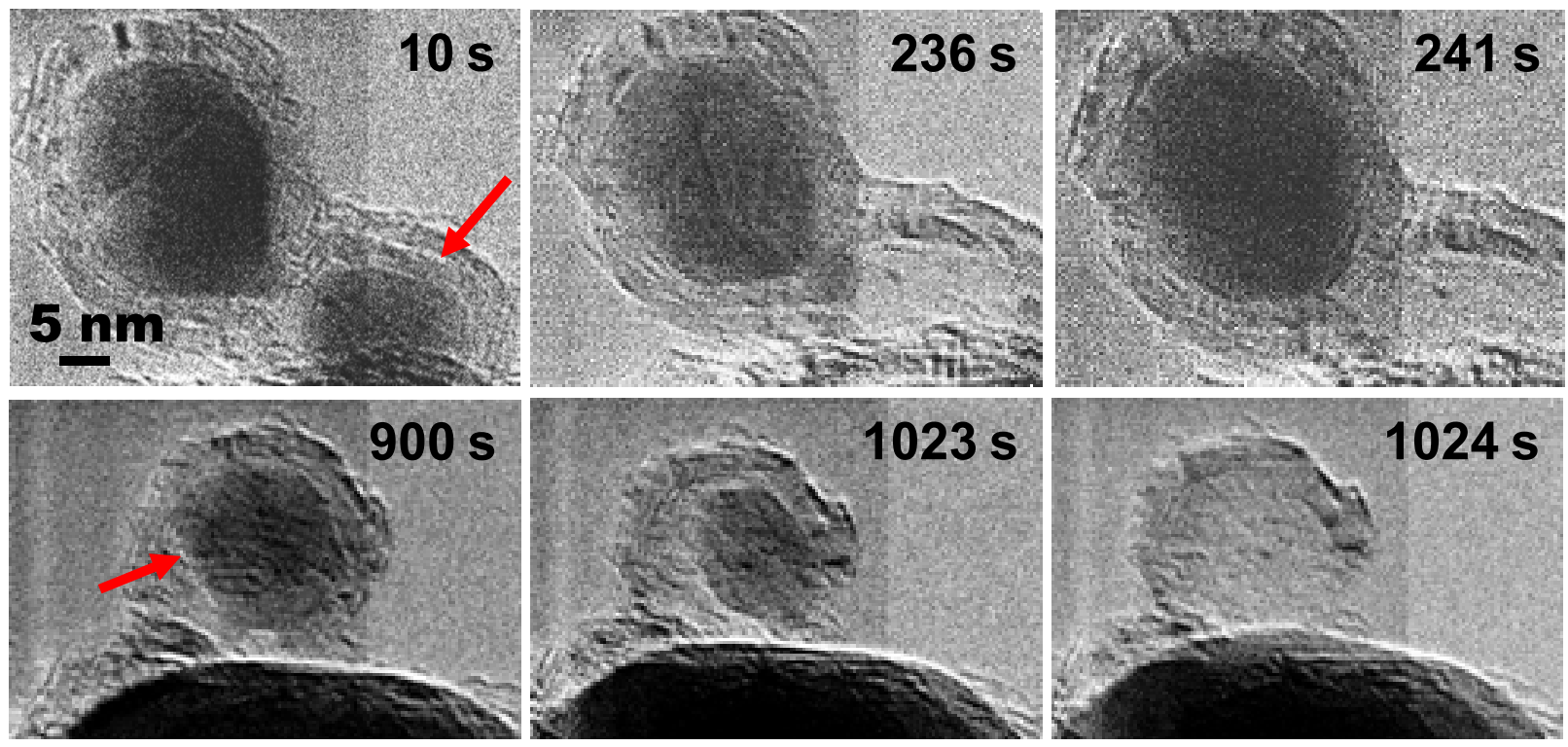

Figure 2. Direct observation of the hollow-core graphitic shells formation on titania at $850{ }^{\circ} \mathrm{C}$. Annealing time is shown on each image. 